\title{
PATHWAY TO PSYCHIATRIC CARE IN PATIENTS WITH ALCOHOL USE DISORDER AT A GENERAL HOSPITAL PSYCHIATRY UNIT IN
}

INDIA

Authors: Dr. Sagar Garag ${ }^{\# 1}$, Dr. Sameer Belvi Mangalwedhe ${ }^{2}$ \#Presenting author,1- Junior Resident Psychiatry, 2-Assistant professor, Karnataka Institute of Medical Sciences, Hubballi
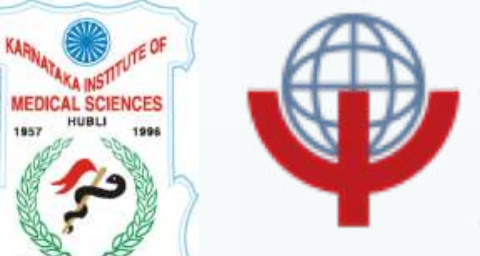

WORLD

PSYCHIATRIC ASSOCIATION
$19^{\mathrm{TH}}$ WPA WORLD CONGRESS OF PSYCHIATRY LISBON, 21-24 AUGUST, 2019

Background Alcohol is a major contributor to mortality and morbidity in India. (1) Knowledge about the help-seeking behavior and pathways to care of patients is pivotal in providing effective planning and early interventions There is limited scientific literature regarding the pathway of care (POC) among individuals with alcohol use disorders and none in general hospital psychiatry units.(2)

Aims and Objectives To study the pathway to psychiatric care in patient with alcohol dependence syndrome.

Methodology A cross-sectional, observational study on 110 male subjects diagnosed with alcohol dependence as per ICD-10. Pathways to care were assessed using the WHO encounter form.(3) Analysis was done in Epi Info TM7. Pathway analysis was done.

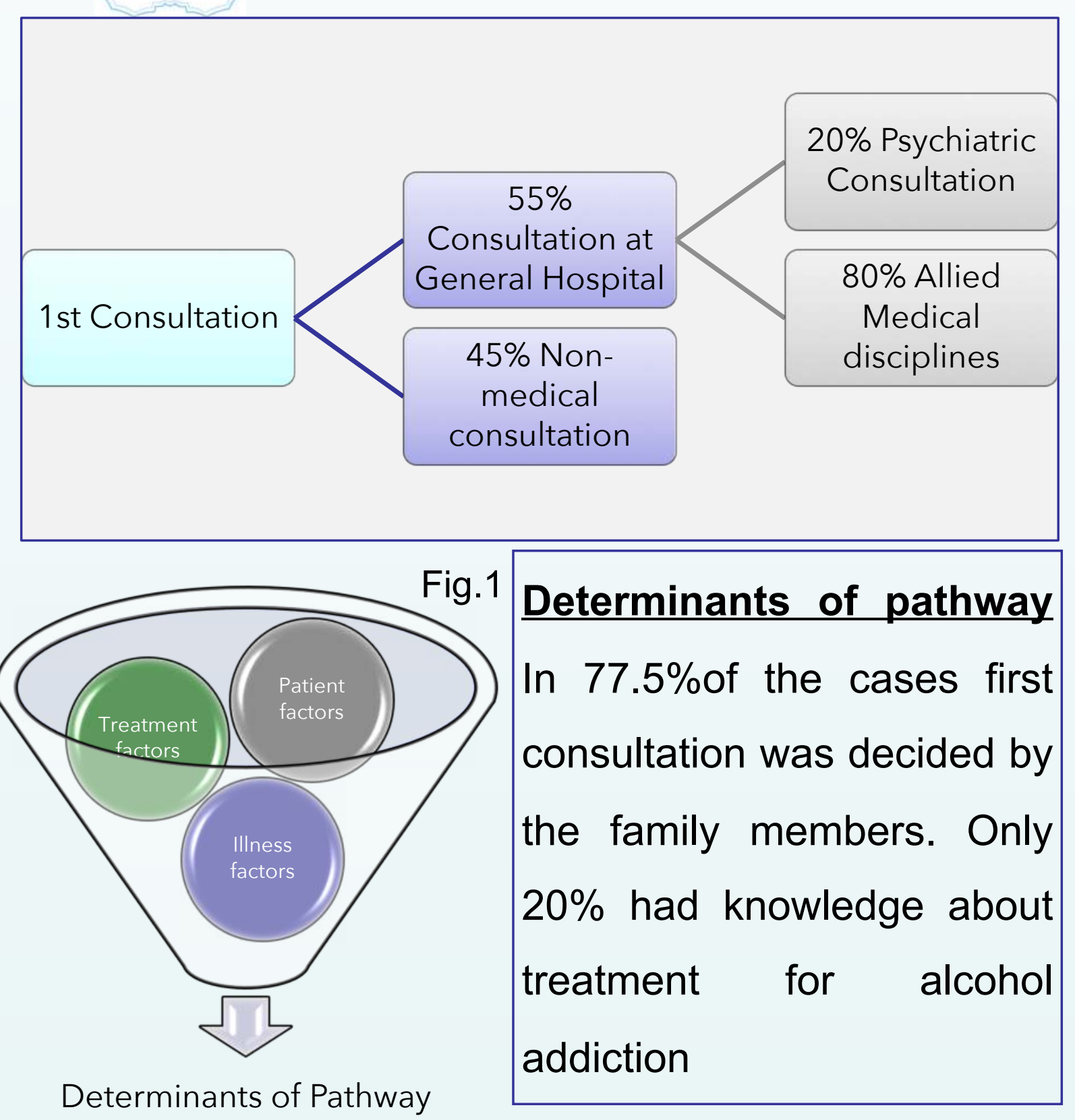

Results The mean age of patients was 38.1yr (SD=7.5). Majority of patients were from urban area(60\%). $25.64 \%$ were illiterate and only $5.13 \%$ were graduates. $50 \%$ were employed. Median duration of untreated illness was 13yr.

Discussion Mean age at first alcoholic drink was 20.5yr $(S D=5)$. Median age at onset of alcohol dependence was 25 years. $57.5 \%$ of patients had severe dependence at the time of first consultation.
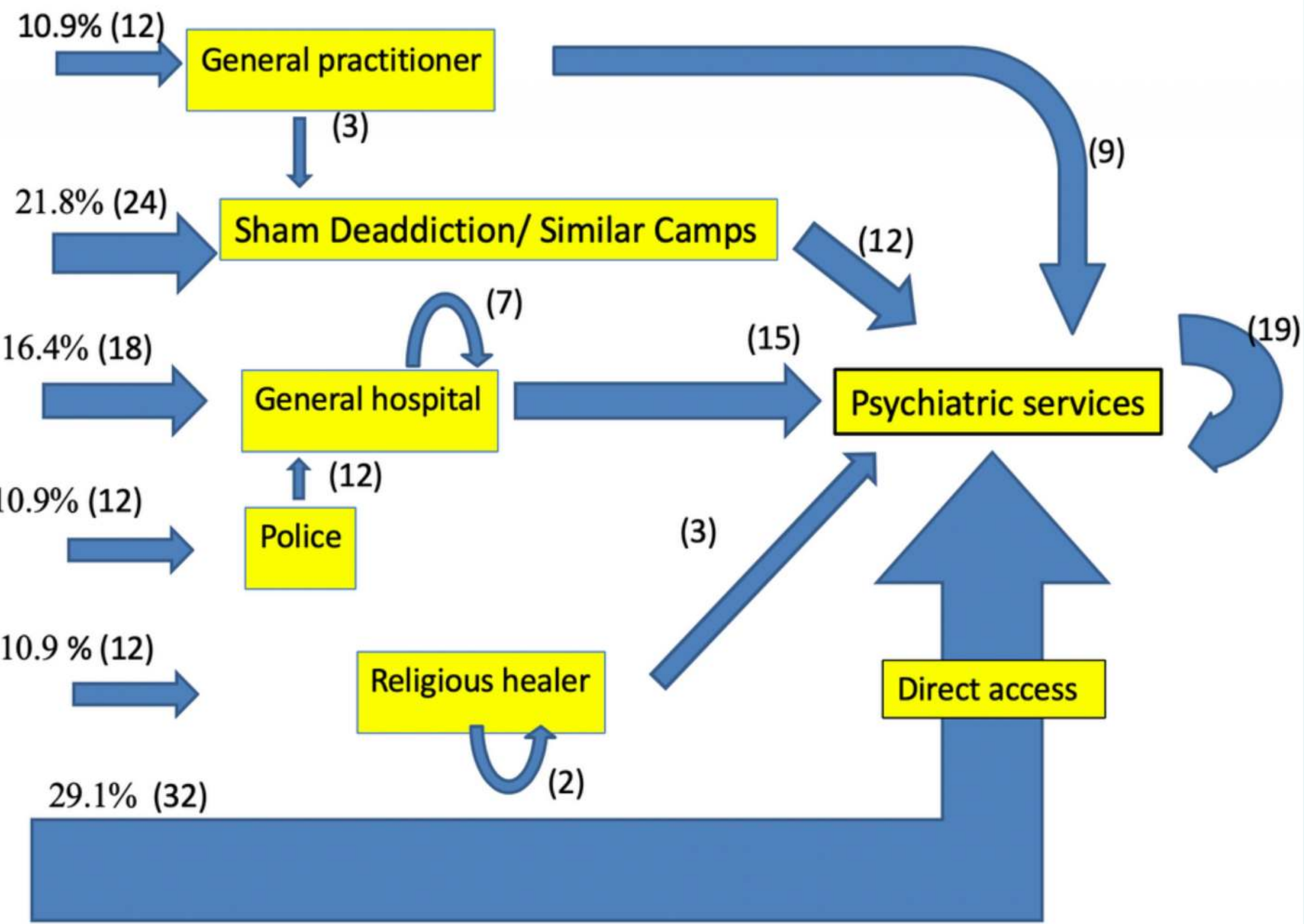

Fig.2 Pathway to Psychiatric care

Conclusion Lack of awareness about treatment and medical model of alcohol use disorder contributes significantly delay in Psychiatric consultation for Alcohol related problems. Creating awareness amongst general public and also medical practitioners regarding the alcohol use disorder is essential.

\section{References}

1.Pal Singh Balhara Y, Prakash S, Gupta R. Pathways to Care of Alcohol -Dependent Patients: An Exploratory Study From a Tertiary Care Substance Use Disorder Treatment Center, Int J High Risk Behav Addict. 2016 ; 5(3):e30342. doi: 10.5812/ijhrba.30342.

2.Kline A. Pathways into drug user treatment: the influence of gender and racial/ethnic identity. Subst Use Misuse. 1996;31(3):323-42. [PubMed: 8834265].

3.Gater R, de Almeida e Sousa B, Barrientos G, Caraveo J, Chandrashekar CR, Dhadphale M, et al. The pathways to psychiatric care: a cross-cultural study. Psychol Med. 1991;21(3):761-74. [PubMed: 1946864]. 